\title{
Future Career Intent of Budding Nurses: A Cross-sectional Descriptive Study in Uttarakhand
}

\author{
Maneesh Sharma ${ }^{1} \odot$, Pooja Lakra², Nikita Arya ${ }^{3}$, Priya Kumari ${ }^{4}$, Pinky Yadav $^{5}$, Payal G Kaur ${ }^{6}$, Ritambra Dadwal ${ }^{7}$, \\ Poonam Verma ${ }^{8}$, Reena Devi ${ }^{9}$, Rasphinder Kaur ${ }^{10}$, Roshni Sinha ${ }^{11}$, Priya Sharma ${ }^{12}$
}

\begin{abstract}
A cross-sectional descriptive study was undertaken to explore the future career intent of outgoing budding nurses of general nursing midwifery (GNM), Bachelor of Science in nursing (BSc Nursing), and Master of Science in Nursing (MSc Nursing). A total of 409 outgoing budding nurses were recruited through the simple random sampling method from conveniently selected nursing colleges of Uttarakhand state. A pre-validated semi-structured questionnaire was administered to collect the data. Result showed that the majority (69.4\%) of participants were from Uttarakhand, about half (48.5\%) of the participants were from urban habitat, and less than half (46.9\%) of the participants have joined nursing by their own interest. The majority (91.4\%) of the participants were not having any plan $8.6 \%$ wished to change the profession, and of these, about one-third (31.4\%) of the participants were not interested in nursing and hence willing to change the profession. About onefourth $(25.5 \%)$ of the participants have shown their willingness to work in teaching, and less than one-fourth (22.7\%) were willing to work at bedside. The majority (78.4\%) of the participants were willing to work in India, whereas $83.1 \%$ had plan for higher education and a vast majority (94.1\%) were willing to work in government sector after completion of their program. The present study concludes that a significant number of participants were willing to work in the country primarily in teaching job followed by bedside especially in government sector.
\end{abstract}

Keywords: Bachelor of Science in Nursing, Budding nurses, Future career intent, General nursing midwifery, Master of Science in Nursing. Pondicherry Journal of Nursing (2021): 10.5005/jp-journals-10084-13105

\section{INTRODUCTION}

Over the past 100 years, the nursing profession has seen tremendous changes in country and globally. National organizational bodies such as Indian Nursing Council (INC) and Trained Nurse Association of India (TNAI) played a remarkable role to bring about this change after their foundation in the years 1908 and 1947. Nursing profession kept on developing, and in the course of recent years, the demeanor of the general public toward it has been changed to some extent. ${ }^{1}$ Globally, there are 19.3 million nurses and midwives according to the WHO's World Health Statistics Report 2011, and the figures reveal that in the shortage of the health workers globally, nurses reflect more than $50 \%$ of shortage currently, which can be seen on a large scale in South-East Asia and Africa. ${ }^{2}$ According to recent article, The US Bureau of Labor Statistics projects that 11 million additional nurses are needed to avoid a further shortage. ${ }^{3}$ Employment opportunities for nurses are projected to grow at a faster rate (15\%) than all other occupations from 2016 through 2026. ${ }^{4}$ A noteworthy fact from 2017 report by WHO on the history of nursing and midwifery stated that nurses will play a critical role in the improvement of health outcomes in the future. ${ }^{2}$ According to recent data from INC, at present the total number of nursing educational institutions in the country is 8,770 , and in Uttarakhand state, 87 nursing colleges are recognized by INC, among which 20 are Bachelor of Science in Nursing (BSc Nursing), 8 are Master of Science in Nursing (MSc Nursing), 7 are Post basic BSc. Nursing, 29 are GNM, 21 are ANM, and 2 are of Post-basic diploma. ${ }^{5}$ In spite of continuous growth in nursing profession over few years, still there is a gap in demand and supply of nurses all across the countries. Globally, there are 1/1,000 doctors and 2.5/1,000 nurses available, whereas the numbers in India are not appreciable too as the figures reflect 0.7 doctors and 1.7 nurses available per thousand of population. ${ }^{1}$ These figures are enough to depict the
${ }^{1-12}$ Department of Nursing, AllMS, Rishikesh, Uttarakhand, India

Corresponding Author: Maneesh Sharma, Department of Nursing, AllMS, Rishikesh, Uttarakhand, India, Phone: +91 9001689135, e-mail: manishsharma740@gmail.com

How to cite this article: Sharma M, Lakra P, Arya N, Kumari P, Yadav P, Kaur PG, et al. Future Career Intent of Budding Nurses: A Cross-sectional Descriptive Study in Uttarakhand. Pon J Nurs 2021;14(2):29-33.

Source of support: Nil

Conflict of interest: None

shortage of nurses and current situation of the healthcare system in India. Government has also noticed a gradual shortage of nurses based on the nursing estimates over the years. The reasons being the lack of facilities, low professional status, lack of educational opportunities, lack of resources, workload and poor working conditions, inappropriate wages, etc. are the major problems associated with the profession. 4,6

In Western countries, nursing is seen as a well-paid career option, ${ }^{7}$ while in India nurses are not been paid well in both private and public sectors. Therefore, student nurses after completion of program try to get an opportunity to work overseas or change the profession. ${ }^{8}$ At present in India no such concrete data are available, which shows about the career option budding nurses choose after completion of their nursing program. ${ }^{9}$ Budding nurses are the student nurses who pursuing nursing program like general nursing midwifery (GNM), BSc Nursing, and MSc Nursing program in various nursing schools and colleges. There are very few research studies conducted on future career intent in the country and revealed a little information in regard to it. However, in Uttarakhand, no such study is undertaken so far best to our knowledge, and no data 
about future career intent were available. Therefore, it is important to gain a deep understanding of career plans of budding nurses choose after completion of nursing program and identify reasons to leave the profession in the mid of the program. A recent study conducted by Brooker et al. ${ }^{10}$ stated that the reasons to leave the nursing profession during the program or after completion were academic failures, personal reasons, stress, poor organization during the course, financial problems in family, and difficulty to fit in the environment of profession, and another study conducted by McLaughlin et al. ${ }^{11}$ has mentioned about the role of family and friends in influencing decision of the student to leave or complete the nursing program. In the present study, budding nurses were the students who were studying in the final year of GNM, BSc. Nursing, and MSc. Nursing program in various nursing schools and colleges of Uttarakhand state. Therefore, in order to explore the future career intent of budding nurses and identify the reasons to change the profession, the present study was proposed. The information obtained from study will serve as a baseline for future studies; it will contribute to bridge the information gap and will provide the information to competent authorities of the state to overcome the shortage of nurses and minimize the migration of nurses to nearby states and overseas. Furthermore, the findings of the study may also be used to frame policy to prevent the dropout of budding nurses in the mid of the program by overcoming issues faced by budding nurses.

\section{Material and Methods}

A cross-sectional descriptive study was conducted among outgoing budding nurses of seven conveniently selected colleges and schools of nursing at Uttarakhand state from May to June 2019. The objective of study was to explore the future career intent of budding nurses choose once they complete their nursing program. There were a total of 7,800 budding nurses studying nursing program in Uttarakhand, out of which 409 sample size was drawn by the simple random sampling method. Sample size was calculated by Open Epi version 3.01 ${ }^{12}$, where the confidence interval was $95 \%$, the hypothesized frequency of outcome factor in population was $50 \% \pm 5$, the confidence limit was $5 \%$, and the design effect was 1 . Calculated sample size was 367 , and by considering the $10 \%$ dropout attrition, the total number of the sample was 409 . Attendance register was used to recruit the participants, and every alternative student on the attendance register was included in the study. Self-structured questionnaire was used to assess the future career intent of budding nurses where the first question was to assess plan to change the nursing profession, and the remaining questions were focused on future career intent. The reliability of the tool was assessed using the test-retest method on a sample of 40 , and the reliability coefficient was obtained to be statistically significant at the level of $0.05(r=0.7)$. The content validity of the tool was established by eight experts in the field of nursing by requesting them to evaluate the questionnaires. Finally, four items on which disagreement among the experts was reported were removed from the final version, and scale content validity index of tool was calculated, which was 0.78 . Students studying in their final year (third year GNM, fourth year BSc. Nursing, second year MSc. Nursing), willing to participate, and present at the time of data collection were included as study participants, and those studying other than above[mentioned years were excluded. Ethical permission was obtained from the Institute Ethical Committee vide letter no 45/IIEC/2019:12.04.2019, and written permission was obtained from competent authorities of the nursing school and colleges for data collection. Participants were informed about the purpose of the study, and informed consent was taken from study participants before the final data collection. The participants were given 15 minutes to complete the data collection. The data analysis was done by using descriptive and inferential statistics. Systematically collected raw data were coded, computed, and analyzed using appropriate descriptive and inferential statistics to generate results. Analysis of the data was done in accordance with the objectives of the study by Statistical Package for Social Science 23. Descriptive statistics was used to categorize the demographic characteristics of the participants. Inferential statistics was done using Chi-square test to find out the association of future career intent with program pursuing by budding nurses.

\section{Results}

The mean age of budding nurses was $21.38 \pm 1.52$ years. The majority of students were from age group of 21 to 24 years comprising GNM (74.4\%), BSc Nursing (74.3\%), and MSc Nursing (84.2\%). The majority of $88.75 \%$ and $88.3 \%$ budding nurses were female and Hindu, while less than one-fourth $(4.9 \%)$ were Muslim followed by $3.9 \%$ and $2.2 \%$ who were Sikh and Christian $(p=0.021)$. About more than half $(69.4 \%)$ of budding nurses were from Uttarakhand followed by 5.9\% from Haryana, 5.1\% from Uttar Pradesh and Delhi, $4.2 \%$ from Punjab, and $10.3 \%$ were from other states of the country $(p=0.000)$. About half of the participants $(48.5 \%)$ were urban dwellers, while $28.9 \%$ and $22.5 \%$ were rural and semi-urban dwellers $(p=0.000)$. In regard to father's occupation, majority (43.28\%) were in government job and the majority (82.6\%) of participants' mothers were housewife $(p=0.004)$. The majority of participants' (28.1\%) monthly family income was between 15,000 and $30,000 /$ month $(p=0.000)$. Regarding the reason to join nursing, the majority (46.9\%) of participants stated own interest; in contrary to that, $24.9 \%$ of participants stated that they did not get admission in medical stream and $22.1 \%$ stated the influence by parents or family, $6.1 \%$ wanted to go abroad, and about more than two-thirds $(83.4 \%)$ of participants were from non-nursing family background ( $p=0.000)$ (Table 1).

In regard to plan to change of profession by budding nurses, the majority (91.4\%) don't want to change the profession, while $8.6 \%$ wished to change the profession. Further when asked about the reason to change the profession, more than one-fourth $(31.4 \%)$ stated that they are not interested in nursing, while $25.7 \%$ felt lack of respect, while $20 \%$ mentioned about inferiority complex, $14.3 \%$ social stigma, and $8.6 \%$ mentioned about health-related issues. Surprisingly, about one-fourth $(25.5 \%)$ of the budding nurses wanted to join teaching after completion of their program and about less than one-fourth (22.7\%) wanted to work at bedside and as independent nurse practitioner, while about $4.8 \%$ wanted to work as administrator and less than one-fourth (24.3\%) of budding nurses have not planned so far for their intent of work $(p=0.001)$. About more than three-fourth $(78.4 \%)$ of budding nurses wish to work in India, while about less than one-fourth (21.6\%) wanted to work in abroad after completion of their program. About more than threefourth (83.1\%) had plan for higher education, while $16.9 \%$ did not have any plan of higher education in the future. The majority (94.1\%) of budding nurses were willing to work in government sector, while very few (5.9\%) wanted to work in the provided sector (Table 2). 
Table 1: Sociodemographic profile of budding nurses $(N=409)$

\begin{tabular}{|c|c|c|c|c|c|}
\hline Sociodemographic variable & GNM & $B S C(N)$ & $M S c(N)$ & Total & Statistical test \\
\hline \multicolumn{6}{|l|}{ Age (in years) } \\
\hline $17-20$ & $23(18.4)$ & $67(25.3)$ & $0(0)$ & $90(22)$ & \multirow{4}{*}{$\begin{aligned} X^{2} & =198.91 \\
p & =0.000^{*}\end{aligned}$} \\
\hline $21-24$ & $93(74.4)$ & $197(74.3)$ & $16(84.2)$ & $306(74.82)$ & \\
\hline $25-28$ & $8(6.4)$ & $1(0.4)$ & $2(10.5)$ & $11(2.69)$ & \\
\hline $29-32$ & $1(0.8)$ & $0(0)$ & $1(5.3)$ & $2(0.49)$ & \\
\hline \multicolumn{6}{|l|}{ Gender } \\
\hline Male & $15(12)$ & $31(11.7)$ & $0(0)$ & $46(11.25)$ & \multirow{2}{*}{$\begin{aligned} X^{2} & =2.53 \\
p & =0.282\end{aligned}$} \\
\hline Female & $110(80)$ & $234(88.3)$ & $19(100)$ & $363(88.75)$ & \\
\hline \multicolumn{6}{|l|}{ Religion } \\
\hline Hindu & $121(96.8)$ & $224(84.5)$ & $16(84.2)$ & $361(88.3)$ & \multirow{5}{*}{$\begin{aligned} X^{2} & =18.08 \\
p & =0.021^{*}\end{aligned}$} \\
\hline Muslim & $2(1.6)$ & $18(6.8)$ & $0(0)$ & $20(4.9)$ & \\
\hline Sikh & $0(0)$ & $14(5.3)$ & $2(10.5)$ & $16(3.9)$ & \\
\hline Christian & $2(1.6)$ & $6(2.3)$ & $1(5.3)$ & $9(2.2)$ & \\
\hline Others & $0(0)$ & $3(1.1)$ & $0(0)$ & $3(0.7)$ & \\
\hline \multicolumn{6}{|l|}{ State of domicile } \\
\hline Uttarakhand & $120(96)$ & $163(61.5)$ & $1(5.3)$ & $284(69.4)$ & \multirow{6}{*}{$\begin{aligned} X^{2} & =155.41 \\
p & =0.000^{*}\end{aligned}$} \\
\hline Uttar Pradesh & $5(4)$ & $15(5.7)$ & $1(5.3)$ & $21(5.1)$ & \\
\hline Haryana & $0(0)$ & $20(7.5)$ & $4(21.1)$ & $24(5.9)$ & \\
\hline Delhi & $0(0)$ & $14(5.3)$ & $7(36.8)$ & $21(5.1)$ & \\
\hline Punjab & $0(0)$ & $15(5.7)$ & $2(10.5)$ & $17(4.2)$ & \\
\hline Others & $0(0)$ & $38(14.3)$ & $4(21.1)$ & $42(10.3)$ & \\
\hline \multicolumn{6}{|l|}{ Habitat } \\
\hline Rural & $48(38.4)$ & $68(25.7)$ & $2(10.5)$ & $118(28.9)$ & \multirow{3}{*}{$\begin{aligned} X^{2} & =35.20 \\
p & =0.000^{*}\end{aligned}$} \\
\hline Urban & $37(29.6)$ & $145(54.7)$ & $17(89.5)$ & 199 (48.5) & \\
\hline Semi-urban & $40(32)$ & 52 (19.6) & $0(0)$ & $92(22.5)$ & \\
\hline \multicolumn{6}{|l|}{ Occupation of father } \\
\hline Private employee & $38(30.4)$ & $72(27.2)$ & $5(26.3)$ & $115(28.1)$ & \multirow{5}{*}{$\begin{aligned} X^{2} & =12.24 \\
p & =0.141\end{aligned}$} \\
\hline Government employee & $49(39.2)$ & $117(44.2)$ & $11(57.9)$ & $177(43.3)$ & \\
\hline Farming & $25(20)$ & $31(11.7)$ & $0(0)$ & $56(13.7)$ & \\
\hline Businessman & $11(8.8)$ & $39(14.7)$ & $2(10.5)$ & $52(12.7)$ & \\
\hline Unemployed & $2(1.6)$ & $6(2.3)$ & $1(5.3)$ & $9(2.2)$ & \\
\hline \multicolumn{6}{|l|}{ Occupation of mother } \\
\hline Private employee & $7(5.6)$ & $14(5.3)$ & $1(5.3)$ & $22(5.4)$ & \multirow{4}{*}{$\begin{aligned} X^{2} & =22.66 \\
p & =0.004^{*}\end{aligned}$} \\
\hline Government employee & $5(4)$ & $33(12.5)$ & $2(10.5)$ & $40(9.8)$ & \\
\hline Housewife & $112(89.6)$ & $212(80)$ & $14(73.7)$ & $338(82.6)$ & \\
\hline Businesswomen & $1(0.8)$ & $6(2.3)$ & $2(0.7)$ & $9(2.2)$ & \\
\hline \multicolumn{6}{|l|}{ Monthly family income } \\
\hline$<15,000$ & $52(41.6)$ & $54(20.4)$ & $0(0)$ & $106(25.9)$ & \multirow{4}{*}{$\begin{aligned} X^{2} & =48.51 \\
p & =0.000^{*}\end{aligned}$} \\
\hline $15,000-30,000$ & $37(29.6)$ & $76(28.7)$ & $2(10.5)$ & $115(28.1)$ & \\
\hline $30,000-45,000$ & $22(17.6)$ & $62(23.4)$ & $4(21.1)$ & $88(21.5)$ & \\
\hline$>45,000$ & $14(11.2)$ & $73(27.5)$ & $13(68.4)$ & $100(24.5)$ & \\
\hline \multicolumn{6}{|l|}{ Reason to join nursing } \\
\hline Own interest & $89(71.2)$ & $99(37.4)$ & $4(21.1)$ & $192(46.9)$ & \multirow{4}{*}{$\begin{aligned} X^{2} & =69.54 \\
p & =0.000^{*}\end{aligned}$} \\
\hline Influence by parents/family & $31(24.8)$ & $54(20.4)$ & $5(26.3)$ & $90(22.1)$ & \\
\hline Wish to go abroad & $3(2.4)$ & $21(7.9)$ & $1(5.3)$ & $25(6.1)$ & \\
\hline Didn't get admission in medical stream & $2(1.6)$ & $91(34.3)$ & $9(47.4)$ & $102(24.9)$ & \\
\hline \multicolumn{6}{|l|}{ Family member in nursing } \\
\hline Yes & $16(12.8)$ & $50(18.9)$ & $2(10.5)$ & $68(16.6)$ & \multirow{2}{*}{$\begin{aligned} X^{2} & =2.79 \\
p & =0.248\end{aligned}$} \\
\hline No & $109(87.2)$ & $215(81.1)$ & $17(89.5)$ & $341(83.4)$ & \\
\hline
\end{tabular}

GNM, General nursing and midwifery; BSc (N), Bachelor of Science in Nursing; MSc (N), Master of Science in Nursing; *Significant at $p$-value $<0.05$ 
Table 2: Future career intent of budding nurses $(N=409)$

\begin{tabular}{|c|c|c|c|c|c|}
\hline Future career intent & GNM & $B S C(N)$ & $M S c(N)$ & Total & Statistical test \\
\hline \multicolumn{6}{|l|}{ Plan to change the profession } \\
\hline Yes & $7(5.6)$ & $26(9.8)$ & $2(10.5)$ & $35(8.6)$ & \multirow{2}{*}{$\begin{aligned} x^{2} & =2.024 \\
p & =0.364\end{aligned}$} \\
\hline No & $118(94.4)$ & $239(90.2)$ & $17(89.5)$ & $374(91.4)$ & \\
\hline \multicolumn{6}{|l|}{ Reason to change the profession } \\
\hline Not interested in nursing & $2(28.6)$ & $8(30.8)$ & $1(50)$ & $11(31.4)$ & \multirow{5}{*}{$\begin{aligned} X^{2} & =8.18 \\
p & =0.416\end{aligned}$} \\
\hline Lack of respect & $1(14.3)$ & $8(30.8)$ & $0(0)$ & $9(25.7)$ & \\
\hline Health-related issue & $0(0)$ & $2(7.7)$ & $1(50)$ & $3(8.6)$ & \\
\hline Inferiority complex & $2(28.6)$ & $5(19.2)$ & $0(0)$ & $7(20)$ & \\
\hline Social stigma & $2(28.6)$ & $3(11.5)$ & $0(0)$ & $5(14.3)$ & \\
\hline \multicolumn{6}{|c|}{ Intent to join after completion of program } \\
\hline Teaching & $30(25.4)$ & $58(24.3)$ & $7(41.2)$ & $95(25.5)$ & \multirow{5}{*}{$\begin{aligned} x^{2} & =29.40 \\
p & =0.001^{*}\end{aligned}$} \\
\hline Bedside & $16(13.6)$ & $66(27.6)$ & $3(17.6)$ & $85(22.7)$ & \\
\hline Administration & $4(3.4)$ & $11(4.6)$ & $3(17.6)$ & $18(4.8)$ & \\
\hline Independent nurse practitioner & $40(33.9)$ & $42(17.6)$ & $3(17.6)$ & $85(22.7)$ & \\
\hline Not yet planned & $28(23.7)$ & $62(25.9)$ & $1(5.9)$ & $91(24.3)$ & \\
\hline \multicolumn{6}{|c|}{ Intent to work after completion of program } \\
\hline India & $100(84.7)$ & $179(74.9)$ & $14(82.4)$ & $293(78.4)$ & \multirow{2}{*}{$\begin{aligned} x^{2} & =4.68 \\
p & =0.096\end{aligned}$} \\
\hline Abroad & $18(15.3)$ & $60(25.1)$ & $3(21.6)$ & $81(21.6)$ & \\
\hline \multicolumn{6}{|l|}{ Plan for higher education } \\
\hline Yes & $103(87.3)$ & $193(80.8)$ & $15(83.1)$ & $311(83.1)$ & \multirow{2}{*}{$\begin{aligned} x^{2} & =2.73 \\
p & =0.255\end{aligned}$} \\
\hline No & $15(12.7)$ & $46(19.2)$ & $2(16.8)$ & $63(16.9)$ & \\
\hline \multicolumn{6}{|c|}{ Preferred sector to work after completion of program } \\
\hline Government & $109(91.5)$ & $226(94.6)$ & $17(100)$ & $352(94.1)$ & \multirow{2}{*}{$\begin{aligned} X^{2} & =2.69 \\
p & =0.240\end{aligned}$} \\
\hline Private & $10(8.5)$ & $12(5.4)$ & $0(0)$ & $22(5.9)$ & \\
\hline
\end{tabular}

*Significant at $p$-value $<0.05$

\section{Discussion}

In this present study, a total of 409 budding nurses from GNM, BSc. Nursing, and MSc. Nursing were included to explore their future career intent. It was noted that the majority of the budding nurses in all streams were females belonging to 21 to 24 years of age group, and the study conducted by Sharma et al. ${ }^{13}$ showed consistent results in this regard where the majority of participants were female. In India, nursing is considered as female-dominated profession; therefore, more female aspirants prefer to choose nursing as their career option as compared to males. The present study had also revealed that the majority of the participants (88.3\%) were Hindus and are in line with the findings of similar studies done by Patidar et al. ${ }^{13}$ and Swarna et al. ${ }^{14}$ where the majority of participants were Hindus.

In regard to state of domicile, most of the participants (69.4\%) were from Uttarakhand and were from urban habitat. Another noteworthy fact that can be linked with the area of residence is the occupation of their fathers' because about half of the participants father were in the government service so it can also be added that the participants were aware of the security and other benefits available in government jobs, and hence, they considered their career as more beneficial in the government job. Similar study done by Motakpalli et al. ${ }^{15}$ has shown difference here in regard to father's occupation where the majority $(60 \%)$ of participants' fathers were private employees, whereas more than half of the participants' mothers were housewives, which has shown resemblance with our study and was also significant. The study found another noteworthy significant fact, which is similar to the study conducted by Patidar et al. $^{13}$ that about half of budding nurses had joined nursing profession at their own will and did not have any kind of influence except half of the participants from MSc. Nursing revealed the reason to join nursing was that they did not get admission in medical stream. One reason for not having any type of influence on them could be because most of the participants' family members were not in nursing, and the same result was also seen in a similar study conducted by Motakpalli et al. ${ }^{15}$ and Kumar et al. ${ }^{16}$ Although studies have not proved the fact that any family member is in the same profession affects the student's decision, but a study conducted by McLaughlin et al. ${ }^{11}$ stated that family that has a positive or negative opinion about that profession can change their mind regarding the same.

In the present study, the majority of budding nurses had no plans to change the profession, which is consistent with the study conducted by Patidar et al. ${ }^{13}$ where the majority of participants have shown unwillingness to change the profession and very few budding nurses who desired to change the profession stated reasons like not interested in nursing, had inferiority complex and social stigma, which was surprising to know that in the present era where nursing is considered a novel profession and service to mankind, such social stigma even exists. One of the reasons to change the profession could be that nursing students do not perceive nursing as a dignified and respectful profession to get due social recognition and equal to other profession in the country. On the contrary, a study conducted by Swarna et al. ${ }^{14}$ found that most of the participants who did not want to change the profession had the reason that nursing is a respectful profession in which we get 
a chance to serve humanity and have personal growth. In regard to the reason to join nursing, the majority of participants stated own interest, which is consistent with the study conducted by Swarna et al. ${ }^{14}$ and Mkala et al. ${ }^{17}$ In regard to participants' intent to join after the completion of their program, participants from each stream expressed different wishes about one-fourth of participants who wanted to join the teaching, whereas the same percentage of them had not yet decided where they would join and an almost equal number of participants aspired to join bedside nursing and independent nurse practitioners, which is in line with the study conducted by Swarna et al. ${ }^{14}$ and Gunawan et al., ${ }^{18}$ which depicts that half of the participants were willing to work at bedside. Another noteworthy finding came out in the present study that more than half of the participants wanted to work in India and had a plan to pursue higher education, and this finding was parallel to a study conducted by Gunawan et al. ${ }^{18}$ On the contrary, results were found inconsistent in this regard with a study conducted by Patidar et al., ${ }^{13}$ which showed that their majority of study participants were more willing to go to abroad thinking that there would be a better opportunities in other countries. This may be due to the fact that in Punjab state, it's a trend that the majority of professionals wish to work overseas; therefore, budding nurses also prefer to work there for better quality of life and pay. In contrary, in Uttarakhand, budding nurses wish to work in their own or nearby states, but they do not prefer to work overseas.

Present study also highlighted preferred sector to work by budding nurses i.e in government or private and it was found that majority of budding nurses were interested to work in government sector. This result was seen consistent with the study conducted by Mkala et al. ${ }^{17}$ and Gunawan et al., ${ }^{18}$ which unveiled that more than half of the participants in their study expressed to be civil servant after completion of course. Based on this finding, it can be predicted that budding nurses were attracted more toward government job due to job security and better pay because in India in private sector nurses are not well paid and working hours are also more as compared to their counterparts.

\section{Conclusion}

The study concluded that few budding nurses stated the reason to leave the profession was not interested in profession followed by the lack of respect. Therefore, it is warranted to have a protocol in place for guidance and counseling for the student nurses at the time of admission so that they can lead in the right direction. Although the majority of participants did not want to change the profession, vast majority of them desired to work in teaching than bedside. In country like India, where there is an acute shortage of nurses to cater the needs of such a large population, it is required for the government to look into the facts and frame policy to attract more budding nurses to work in bedside also; the competent authorities should frame the policies to attract more budding nurses to work in private sector too by improving working environment and propose reasonable incentives to them as private hospitals also cater the large number of patients in the country.

\section{Limitation}

This study was limited to only nine nursing institutions, and single state due to time constraints; therefore, the generalizability of findings to the entire population is the limitation of the present study. A large-scale multistate study on larger sample size can be conducted in the future.

\section{ORCID}

Maneesh Sharma ำ https://orcid.org/0000-0003-0204-2258

\section{References}

1. Kumar TD, Ezhilarasu P. Growth of nursing in India: historical and future perspectives. Healthy India Chronicle. August 9, 2017.

2. World Health Organization. Nursing and midwifery. Key facts. January 9, 2020.

3. Neilson GR, Lauder W. What do high academic achieving school pupils really think about a career in nursing: analysis of the narrative from paradigmatic case interviews. Nurse Educ Today 2008;28(6):680-690. DOI: 10.1016/j.nedt.2008.03.008.

4. Haddad LM, Annamaraju P, Toney-Butler TJ. Nursing shortage. InStatPearls, 2021.

5. List of Nursing Institutes. Indian Nursing Council. Google Search [Internet].

6. Gill R. Nursing shortage in India with special reference to international migration of nurses. Soc Med 2011;6(1):52-59.

7. Rognstad MK, Aasland O, Granum V. How do nursing students regard their future career? Career preferences in the post-modern society. Nurse Education Today 2004;24(7):493-500. DOI: 10.1016/ j.nedt.2004.07.015.

8. Kershaw $B$. The future of nursing: leading change, advancing health. Nurs Stand 2011;26(7):31. DOI: 10.7748/ns2011.10.26.7.31.b1274.

9. Deodhar AA. Nursing in India: awaiting a bright future. Express HealthCare; 2015.

10. Brooker A, Brooker S, Lawrence J. First year students' perceptions of their difficulties. Student Success 2017;8(1):49. DOI: 10.5204/ssj.v8i1.352.

11. McLaughlin K, Moutray M, Moore C. Career motivation in nursing students and the perceived influence of significant others. J Adv Nurs 2010;66(2):404-412. DOI: 10.1111/j.1365-2648.2009.05147.x.

12. Open Epi. Sample size calculator. 2013. Available from: https://www. openepi.com/Menu/OE_Menu.htm.

13. Patidar AB, Kaur J, Sharma SK, Sharma N. Future nurses' perception towards profession and carrier plans: A cross sectional survey in state Punjab. Nursing and Midwifery Research Journal. 2011 Oct;7(4). DOI: 10.33698/NRF0131

14. Swarna S. Nursing students perception towards profession and future intentions. J Nurs Health Sci 2015;4(5):30-34. DOI: 10.9790/195904513034.

15. Motakpalli K, Shaheen S, Jamadar D, Bendigeri ND. Futuristic perception and carrier aspects of nursing profession among nursing students at Kalaburagi city, Karnataka. Int J Commun Med Public Health 2018;5(9). DOI: 10.18203/2394-6040.ijcmph20183406.

16. Kumar R. Academic climate, academic stress and self esteem among baccalaureate nursing students. Nurs Midwifery Res J 2018;14(2):53. DOI: $10.13140 / R G .2 .2 .19126 .14408$.

17. Mkala B. Nursing as a career: First year Students' perception of and the reasons for their choice of nursing as a career. 2013.

18. Gunawan J, Aungsuroch Y, Sukarna A, Wahab N. Nursing students plan after graduation: a qualitative study. J Educ Health Promot 2018;7(1):1. DOI: 10.4103/jehp.jehp_18_17 